\title{
Accuracy of compressed sensing for left ventricular mass and volumes
}

\author{
Suzanne Lydiard', Andreas Greiser², Michaela Schmidt², Michael O Zenge², Mariappan S Nadar ${ }^{3}$ Alistair Young ${ }^{4}$, \\ Brett R Cowan ${ }^{1 *}$ \\ From 17th Annual SCMR Scientific Sessions \\ New Orleans, LA, USA. 16-19 January 2014
}

\section{Background}

While SSFP CMR is the gold standard for assessing left ventricular (LV) function, it requires a regular cardiac rhythm and frequent breath-holds and not all patients with cardiovascular disease are able to achieve this. It is known that Compressed Sensing (CS) greatly reduces data acquisition time however its accuracy for LV volume and mass is currently unknown. This study compares ventricular function measurements by CS to those obtained from standard SSFP cines.

\section{Methods}

Twenty healthy human subjects (9 male, $40 \pm 14$ years) underwent LV SSFP imaging on a MAGNETOM Skyra 3T scanner (Siemens, Germany). Three sequences were acquired (i) gold standard fully sampled SSFP (FULL) and two 2D prototype sequences featuring CS reconstruction and regularisation in space and time with acceleration factors (ii) $\mathrm{R}=4$ (R4) or (iii) $\mathrm{R}=9.2$ (R9.2). 5-8 short axis slices (thickness $6 \mathrm{~mm}$, slice gap $9 \mathrm{~mm}$ ) and three long axis slices (4-,3-,2-chamber), FOV $=260$ $340 \mathrm{~mm}$, were acquired for each sequence. FULL images were acquired over 14 heart-beats with $\mathrm{TE}=1.54 \mathrm{~ms}, \alpha$ $=51^{\circ}, 25$ frames, matrix $256 \times 256$ and iPAT factor 2 . R4 images were acquired over 4 beats with $\mathrm{TE}=1.29 \mathrm{~ms}, \alpha$ $=41^{\circ}, 21$ frames, matrix $192 \times 143$ with iPAT. R9. 2 images were acquired over 2 beats (one dummy beat for steady state preparation, thereby representing 'realtime' acquisition) with $\mathrm{TE}=1.27 \mathrm{~ms}, \alpha=42^{\circ}, 19$ frames, matrix $192 \times 129$. Images were reconstructed on-line using a non-linear iterative CS method with $\mathrm{k}$-t regularisation derived from a SENSE type reconstruction [1]. Ventricular volume and mass were measured by two analysts blinded to image type using CIM Version 7 and averaged.

\section{Results}

R4 produced comparable end-diastolic volume (EDV) and ejection fraction (EF) results but there were significant differences in end-systolic volume (ESV) and LV mass (LVM). R9.2 results were comparable for ESV but significantly different for EDV, EF and LVM. While statistically significant, these differences were small and consistent, and similar to other acceleration techniques $[2,3]$. To quantify the clinical significance of these results, effect sizes (ES) were calculated, with only EF showing any significance difference for R4 and R9.2.

\section{Conclusions}

These in-vivo results suggest that CS may be used to efficiently assess ventricular function in normal subjects. Testing on pathological cases is required to further support this conclusion. Further optimization of the sampling pattern and image reconstruction parameters is also likely to improve image quality and reconstruction times.

\section{Funding}

Siemens Medical Systems. 
Table 1 LV functional parameters for the FULL acquisition, and difference from this for each accelerated sequence.

\begin{tabular}{ccccc}
\hline & $\begin{array}{c}\text { EDV } \\
\text { mean } \pm \mathbf{s t d}(\mathbf{m L})\end{array}$ & $\begin{array}{c}\text { ESV } \\
\text { mean } \pm \mathbf{s t d}(\mathbf{m L})\end{array}$ & $\begin{array}{c}\text { EF } \\
\text { mean } \pm \text { std (\%) }\end{array}$ & $\begin{array}{c}\text { Mass } \\
\text { mean } \pm \mathbf{s t d}(\mathbf{g})\end{array}$ \\
\hline FULL & $146.0 \pm 31.6$ & $56.9 \pm 16.3$ & $61.4 \pm 4.0$ & $113.9 \pm 30.3$ \\
\hline FULL minus R4 & $-1.2 \pm 5.5$ & $-2.4 \pm 3.4^{*}$ & $1.4 \pm 1.9$ & $-7.2 \pm 7.1^{*}$ \\
\hline FULL minus R9.2 & $7.3 \pm 5.8^{* *}$ & $-2.7 \pm 4.8$ & $4.1 \pm 2.6^{* *}$ & $-4.7 \pm 6.2^{* *}$ \\
\hline
\end{tabular}

p values represent repeated measures Bonferroni corrected ANOVA, ${ }^{*}$ represents $0.05<p<0.01,{ }^{* *}$ represents $p<0.01$

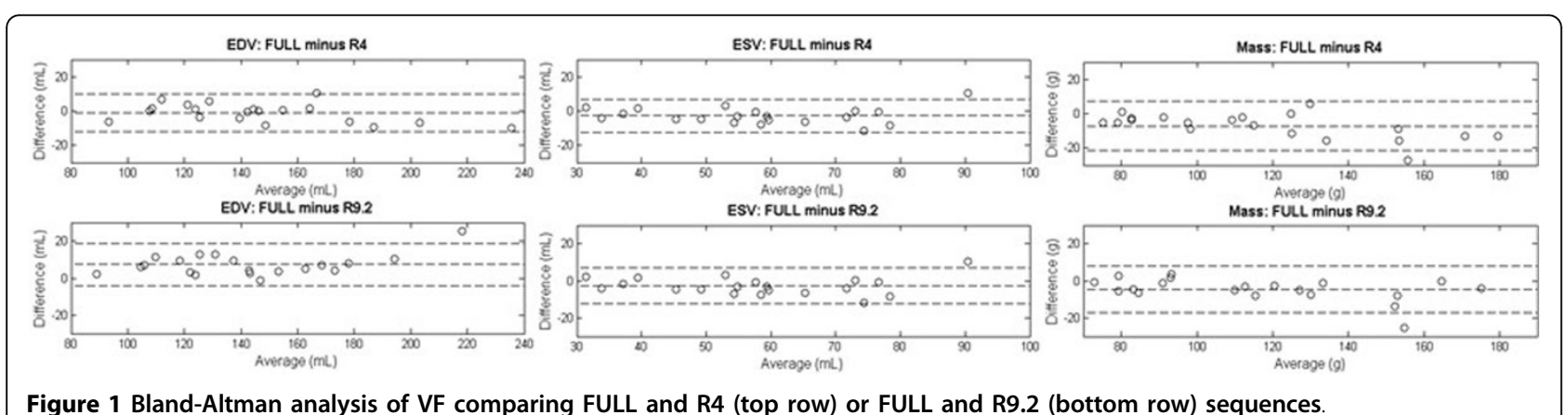

Figure 1 Bland-Altman analysis of VF comparing FULL and R4 (top row) or FULL and R9.2 (bottom row) sequences

\section{Authors' details}

'Auckland MRI Research Group, University of Auckland, Auckland, New Zealand. ${ }^{2}$ Healthcare Sector, Siemens AG, Erlangen, Germany. ${ }^{3}$ Siemens Corporate Research, Siemens AG, Princeton, New Jersey, USA. ${ }^{4}$ Centre for Advanced MRI, University of Auckland, Auckland, New Zealand.

Published: 16 January 2014

\section{References}

1. Beck A: SIIMS 2009, 2:183

2. Feng: MRM 2013, 70:64.

3. Young: JCMR 2008, 10:24.

\section{doi:10.1186/1532-429X-16-S1-P381}

Cite this article as: Lydiard et al: Accuracy of compressed sensing for left ventricular mass and volumes. Journal of Cardiovascular Magnetic

Resonance 2014 16(Suppl 1):P381.

Submit your next manuscript to BioMed Central and take full advantage of:

- Convenient online submission

- Thorough peer review

- No space constraints or color figure charges

- Immediate publication on acceptance

- Inclusion in PubMed, CAS, Scopus and Google Scholar

- Research which is freely available for redistribution 